\title{
Fabrication of Radio-Frequency Micropotentiometer Resistance Elements
}

\author{
Lewis F. Behrent
}

\begin{abstract}
Disk resistors between 1 and $10^{3}$ milliohms needed for the radio-frequency micropotentiometer were not available. Therefore, considerable research was necessary on a wide variety of processes for forming thin-film elements. Those methods whereby resistors stable to within plus or minus 1 percent were consistently produced are described in detail, and the various limitations, fabrication problems, and solutions to these problems are discussed.
\end{abstract}

\section{Introduction}

With the rapid growth of the electronics field, particularly in the past decade, there has been an increasing need for accurate voltage standards in the microvolt range for radio-receiver sensitivity measurements, field-intensity determinations, the calibration of $\mathrm{r}-\mathrm{f}$ signal generators, and other applications. At the present time an accuracy of \pm 1 percent has beeome highly desirable. A device dereloped to meet this need, called the r-f micropotentiometer, ${ }^{1,2}$ provides an accurate, portable, and rugged lowimpedance source of $\mathrm{r}-\mathrm{f}$ voltages from 1 to $10^{5} \mu \mathrm{v}$ for use both in the laboratory and in the field. To achieve a low-output impedance of 1 to $10^{3}$ milliohms, it was necessary to develop low-resistance disk elements. Research was conducted on a great many different processes for making thin-film resistive elements, to determine which consistently produced elements having the requisite stability of \pm 1 percent over lono periods of time and a satisfactorily flat frequency characteristic to at least $300 \mathrm{Mc}$.

The following processes were tried: (a) clamping of resistive disks, (b) low-temperature painting and baking, (c) high-temperature firing, (d) evaporation and plating, and (e) chemical reduction. Only three processes will be described here, that is, high-temperature firing, evaporation and plating, and clamping. Low-temperature paints proved unsatisfactory, whereas the value of the chemical-reduction process has not been fully determined.

\section{General Description}

Basically, a micropotentiometer consists of a disk resistor element whose $\mathrm{r}-\mathrm{f}$ impedance is resistive, the same as for direct current, and some means to indicate the potential across that element. For example, figure 1 , a, shows such a resistor terminating an essentially lossless coaxial line. The input voltage to the line, (1 to $10 \mathrm{v})$, may be measured accurately by means of a calibrated r-f voltmeter. The current at the resistive element is

Radio-frequency micropotentiometers, NBS Tech. News Bul. 35, 33-34

(March 1951).
2 M. C. Selby, Accurate $r-f$ microvoltages, Communications and Electronics, AIEE, No. 6, 158-164 (May 1953).

$$
I_{R}=\frac{E_{S}}{Z_{L} \cos \beta l+j Z_{0} \sin \beta l},
$$

where at a given frequency

$I_{R}=$ current at the resistive element, amperes

$E_{S}=$ r-f voltage input to the line, volts

$Z_{L}=$ impedance of the resistive element, ohms

$Z_{0}=$ characteristic impedance of the line, ohms

$\beta=2 \pi / \lambda$

$l=$ electrical length of the line, centimeters

$\lambda=$ wavelength of the $\mathrm{r}-\mathrm{f}$ signal in the line, centimeters.

Therefore,

$$
E_{R}=I_{R} Z_{L}=\frac{E_{S} Z_{L}}{Z_{L} \cos \beta l+j Z_{0} \sin \beta l}
$$

where $E_{R}$ is volts at the resistive element. At those frequencies where $l$ is an odd multiple of $\lambda / 4$, eq (2) reduces simply to

$$
E_{R}=\frac{E_{S} Z_{L}}{Z_{0}}
$$

Figures 1, b, and 1, c, illustrate a thermoelement and a bolometer, respectively, used to measure the current flowing in the resistor, $R$. For these latter applications the current monitor is considered as having no frequency error even at the highest radio frequency used.

By using resistances of from 1 milliohm to $1 \mathrm{ohm}$ in combination with current levels between 1 and $100 \mathrm{ma}$, levels from 1 to $10^{5} \mu \mathrm{v}$ can be made available. The voltage range may be extended to lower or higher values. However, the use of higher resistances may make it necessary to correct for the impedance of some external circuits connected across the resistance element.

The resistance of an annular ring is principally a function of its physical dimensions and the electrical conductivity of the resistive material used. ${ }^{3}$ Expressed mathematically,

$$
R=\frac{1}{2 \pi \sigma d} \ln \gamma
$$

W. Jackson and L. G. H. Huxley, The solution of transmission-line problems by use of the circle diagram of impedance, Trans. IE E 91, No. III (London, 1944). 


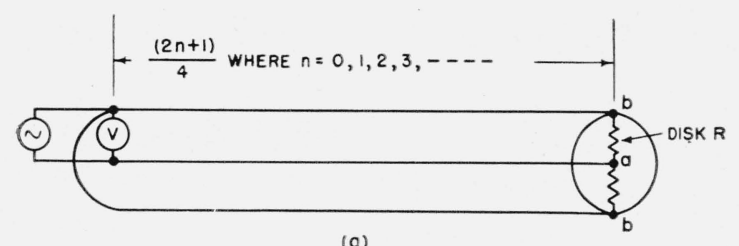

(0)

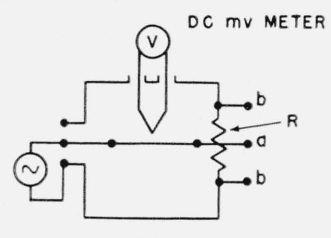

(b)

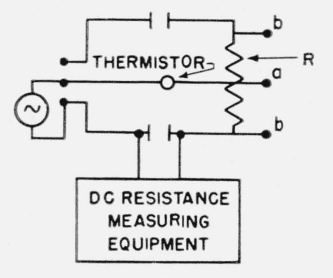

(c)

FIGURE 1. Schematics of three types of radio-frequency micropotentiometers.

$\mathrm{R}$, disk resistive element; $\mathrm{RF}$ output is obtained across the coaxial connector ab. a, coaxial line; b, thermoelement; and $c$, thermistor.

where

$\mathrm{R}=$ resistance of the annular ring, ohms

$\sigma=1 / \rho=\mathrm{mho} / \mathrm{cm}^{3}$

$\gamma=r_{2} / r_{1}$

$d=$ thickness of the resistive film, centimeters

$r_{1}=$ inner radius of the annular ring, centimeters, or inches

$r_{2}=$ outer radius of the annular ring, centimeters, or inches

$\rho=$ resistivity of the metal, ohms $/ \mathrm{cm}^{3}$

A basic sectional line drawing of a typical resistive element and the coaxial electrodes with which it is in contact, figure 2, identifies the dimensions $r_{2}, r_{1}$, and $d$ in eq (4). When the resistive film was formed by firing conductive paints containing the noble metals, the resistance values obtained were somewhat greater than calculations would indicate because of the physical properties of the film so formed.

At zero frequency the current flowing in a conductor is uniformly distributed over its entire cross section. However, as the frequency is increased, there is a greater concentration of the current close to the surface, thereby increasing the resistance above its d-c value. This phenomenon ${ }^{4}$, known as "skin effect", must be largely eliminated in the resistive element of the micropotentiometer, where the convenience of operating with $\mathrm{d}-\mathrm{c}$ calibration values is desirable.

The depth of $\mathrm{r}-\mathrm{f}$ current penetration, $\delta$, in a thick, solid metal is given by

$$
\delta=\left(\frac{1}{\sigma_{m} \pi f \mu_{m}}\right)^{\frac{1}{2}}
$$

where

$\delta=$ depth of penetration in meters

$\sigma_{m}=$ conductivity of the metal

$j=$ frequency of the applied current in $\mathrm{c} / \mathrm{s}$

$\mu_{m}=4 \pi \times 10^{-7} \mathrm{i} / \mathrm{m}$ for nonferrous metals.

${ }^{4}$ F. E. Terman, Radio engineering handbook, p. 34. (McGraw-Hill Book Co., Inc., New York, N. Y., 1943).

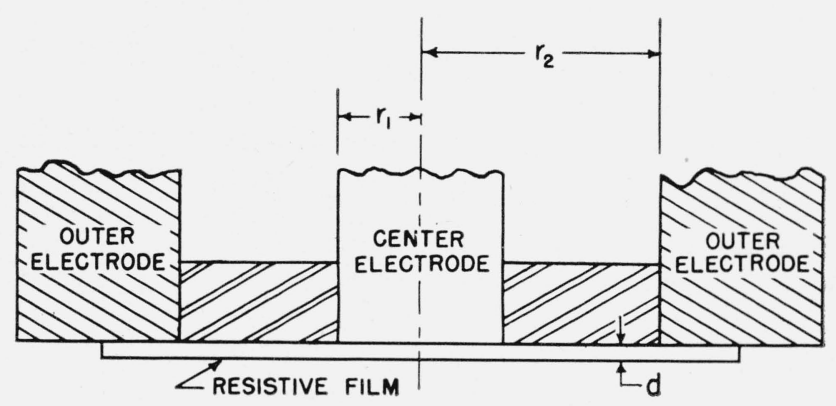

Figure 2. Cross-sectional line drawing of resistive element, showing the electrodes and the resistive film.

Considering the thin-film annulus as a section of coaxial line with a solid conductor as the propagation medium, the transfer impedance, as derived from transmission-line theory, is, for all practical purposes, given by

$$
Z_{m}=R_{m}\left[1-j \frac{d^{2}}{3 \delta^{2}}-\frac{7}{90} \frac{d^{4}}{\delta^{4}}-\ldots\right],
$$

where

$Z_{m}=$ transfer impedance, ohms

$R_{m}=$ d-c resistance of the annulus, ohms

$d=$ film thickness, centimeters.

If at any given frequency $d \leq 0.5 \delta$, the r-f current penetration is very nearly complete and the $r-f$ impedance differs from the $d-c$ resistance by less than 1 percent.

\section{Fabrication Problems and Tests}

There are several problems common to all methods described in this report for fabricating low resistances from thin films. Because these difficulties impose limitations upon the usefulness of the completed element, and may even render it useless, each of these problems will be examined. However, the specific solutions will be presented later in the discussion of fabrication techniques.

\subsection{Radio-Frequency Characteristics and Stability}

The r-f impedance of a resistor element will be frequency-sensitive if (a) the coaxial electrodes fail to contact the film along uniform concentric rings, that is, if the contact areas are irregular and spotty so that the width of the annulus between them is not uniform, (b) the thickness of the film in the annulus is uneven, or (c) the electrodes overlap some part of the resistor while remaining insulated from it. Any combination of these conditions may be found in a single resistive element. Where condition (a) is found, generally condition (c) also exists. The first produces an unsymmetrical distribution of current in the annulus resulting in a series inductive reactance, whereas the latter, because of the capacitance between the film and the electrodes, foreshortens the $r-f$ current path thereby reducing the $r-f$ resistance. Therefore, these effects tend to compensate each other. Unsymmetrical distribution of the current 
in the ring is also caused by uneven film thickness. Resistor instability is caused by poor electrical contact between the film and the electrodes, or results from the flaking off or migration of film particles in the annulus. After sufficient skill is developed in applying the techniques described, the percentage of unstable elements should be very small. Laboratory tests during the past 2 years on resistive elements made from clamped carbon disks, fired-on conductive paints, and evaporated-and-plated films have established that such elements remain stable to \pm 1 percent or better.

\subsection{Power Dissipation and Mechanical Ruggedness}

Because the micropotentiometer is primarily intended for use at levels between 1 and $10^{5} \mu \mathrm{v}$, it is usually unnecessary to apply more than 100 ma to any resistive element. Experimentally, it was found that all types are capable of carrying at least five times this current without deleterious effects. Therefore, there is no power-dissipation problem.

Resistive elements made by the evaporation and plating technique were more fragile and susceptible to mechanical injury than those made by the other processes. Mechanical shock or abrasion can break the film loose from its supporting base (substrate), to which it is bonded only by the keying action of the film particles. The stresses applied to the center in normal use of all types of elements may cause deterioration of electrical contact to the film, and an unstable element, unless the coaxial electrodes and the separating dielectric are firmly joined.

\subsection{Temperature Effect}

When the $r$-f micropotentiometer is used solely in the laboratory where the ambient temperature never varies by more than a few degrees, the error in resistance due to temperature variations will seldom exceed 1 percent. However, a micropotentiometer used in the field may be subjected to a wide range of ambient-temperature conditions. In this case, for resistive materials havi.ig a high-temperature coefficient of resistance, errors of 5 to 6 percent are possible. To determine how serious this problem might become, 1-ohm disk resistors made from carbon sheet, 25 ohms per square, evaporated, and plated silver film resistors and disks made from Hanovia fired-on

\section{TABLE 1.}

\begin{tabular}{|c|c|}
\hline Resistive material & $\begin{array}{l}\text { Mean- } \\
\text { temperature } \\
\text { coefficient of } \\
\text { resistance, } \\
\alpha_{t^{*}}\end{array}$ \\
\hline $\begin{array}{l}\text { Hanovia silver paint No. } 38 \\
\text { Evaporated and plated silver } \\
\text { Hanovia platinum-gold paint No. } 1 \\
\text { Hanovia platinum No. 14. } \\
\text { Carbon sheet, } 25 \text { ohms per square }\end{array}$ & $\begin{array}{r}3 \times 10^{-1} \\
3 \times 10^{-1} \\
5.5 \times 10^{-2} \\
7 \times 10^{-2} \\
8 \times 10^{-3}\end{array}$ \\
\hline
\end{tabular}

${ }^{*} \alpha t$ is the percentage in resistance per deg C. conductive paints (platinum No. 1, platinum No. 14, and silver No. 38) were tested over a temperature range from $5^{\circ}$ to $50^{\circ} \mathrm{C}$. The mean-temperature coefficient of resistance, $\alpha_{t}$, in this temperature range for each of the above materials is presented in table 1 .

\subsection{Factors Limiting the Resistance Range}

For a given resistive material, a resistance range of about 10 to 1 may be obtained merely by using different film thicknesses. Solid films of metal less than $25 \mathrm{~m} \mu$ thick cannot be relied upon because of a tendency to break up. ${ }^{5}$ The metal film may form into droplets because of the surface tension, or particles may migrate until the surface consists of unconnected agglomerates of the metal. Film thickness may be increased as long as the above current penetration requirements are met.

\subsection{Initial Tests and Life Tests}

It has been found, experimentally, that structural imperfections affecting the stability and frequency characteristics of resistive elements do not ordinarily alter the d-c resistance sufficiently to be detected by simple d-c measurements. A simple and accurate initial test that may be used is to incorporate the element in a micropotentiometer and compare the voltage drop across its output with an accurately known $r-f$ voltage or with the output from other tested micropoteatiometers. In figure 3, a the known reference voltage is provided by another micropotentiometer, $M_{1}$. Both it and the unknown, $M_{2}$, are connected in parallel branches to the same $\mathrm{r}-\mathrm{f}$ source. Thus frequency drift either in the receiver or the generator has negligible effect. The transfer instrument is any $\mathrm{r}-\mathrm{f}$ detector, usually a receiver, having a sensitivity of $1 \mu \mathrm{v}$, or better. The $\mathrm{r}-\mathrm{f}$ cur-
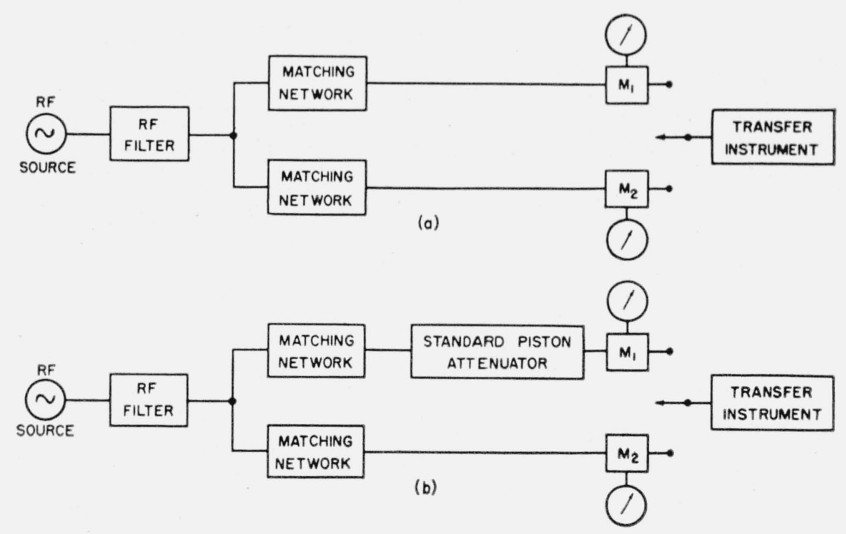

FiguRE 3. Block diagrams of methods for comparing an unknown micropotentiometer versus a tested one.

a, Direct comparison; $b$, comparison of widely different units using a standard attenuator. ${ }^{5}$ Robert G. Picard and O. S. Duffendack, Studies on the structure of thin
metallic_films by means of the electron microscope, J. Appl. Phys. 14, 291-305 metallic 
rent into each micropotentiometer is adjusted until the voltage output is the same for both, as determined by the transfer instrument. Then each thermoelement is calibrated with direct current to determine the $\mathrm{r}-\mathrm{f}$ currents that flowed in the resistive elements, and the output voltages are calculated from Ohm's Law. In matching the output voltages the current levels may reach extremes that are difficult to measure accurately if the resistances of the micropotentiometers are widely different. For example, ambient temperature variations materially reduce the accuracy with which a current of 20 percent or less of the full rated value flowing in a given thermoelement can be measured. A standard waveguidebelow-cutoff attenuator is placed in series with the higher resistance micropotentiometer, $M_{1}$, as shown in figure $3, b$, to keep the r-f-current levels within reasonable limits. The $\mathrm{r}-\mathrm{f}$ input to each branch is adjusted to give full rated current in the thermoelemejt of each micropotentiometer, the attenuator in the $M_{1}$ branch having been set at some convenient low attenuation level. The r-f output of $M_{1}$ is then reduced to match that of $M_{2}$ by adjusting the standard attenuator. This is possible because the heater resistance of the thermoelement in the $M_{1}$ bianch changes by a negligible amount with change in the heater current.

The final voltage output of $M_{1}$ is

where

$$
V_{M_{1}}=V_{0} \times \Delta A
$$

$V_{0}=$ voltage drop across the output of $M_{1}$ for full rated current,

$\Delta A=$ change in attenuation, as a voltage ratio $<1$, required to reduce $V_{0}$ to match $V_{M_{2}}$.

Differences in the output voltages calculated for each of the micropotentiometers are caused by structural defects.

This same test, repeated at intervals of from 2 to 4 weeks for a period of 6 months, constitutes a test for the quality of fabrication techniques when a process has first been put into operation. From actual tests it was found that a better indication of quality can be obtained at high radio frequencies.

\section{Fabrication Processes}

\subsection{Clamped Elements}

A carbon disk clamped to coaxial electrodes provided a very stable type of resistor element. Figure 4 is a partially exploded view of such an assembly. The disk depicted in figure 5 was cut from a commercial carbon sheet consisting of a very thin carbon film deposited on a backing of Bakelite. Because this card material was available in a number of resistance values, it was important to select one that would provide an annular resistive element of reasonable physical dimensions. Fabrication of resistances smaller than $1 \mathrm{ohm}$ was attempted by

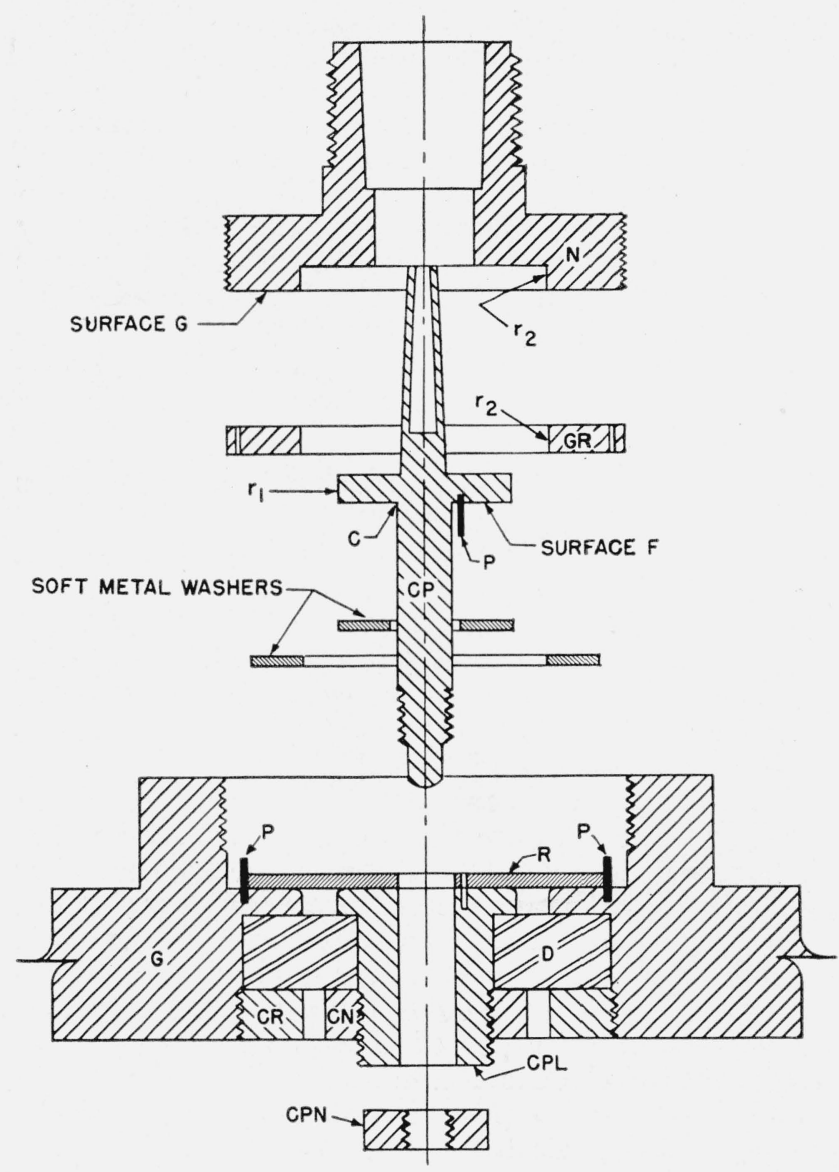

FigURE 4. Blown-up view of a clamped-type resistive element.

CPN, Brass nut; CPL, brass center electrode; GR, brass electrode; CR, brass clamp ring; $\mathrm{CN}$, brass clamp ring; $\mathrm{D}$, dielectric; $\mathrm{G}$, brass ground shell; $\mathrm{P}$, metal pins; $\mathrm{CP}$, brass center electrode; $\mathrm{N}$, brass outer ground shell; $\mathrm{R}$, carbon coaxial resistor.

reducing the width of the annulus, but it was extremely difficult to obtain satisfactory results when the width was made less than $1 \mathrm{~mm}$. As the resistance decreases logarithmically with the decrease in diameter ration, $\gamma$, this method was not the correct approach. The reduction in $\gamma$ necessary to produce an appreciable decrease in resistance resulted in such close spacing of the electrodes that the shunting capacitance between them became rather high. Inasmuch as the resistance per square was known, it was more convenient to determine $\gamma$ for a particular resistance, $R$, from eq (8), the equivalent of eq (4), except for rearranged constants.

$$
\gamma=\log ^{-1}\left(\frac{R}{0.367 S}\right),
$$

where $S$ is the specific resistance of the carbon sheet in ohms per square. An inver radius, $r_{1}$, of $\frac{1}{2}$ in. was used to provide enough area for the center mounting hole, and an adequate contact area for the center electrode. The maximum radius of the disk was made $1 / 8$ in. larger than $r_{2}$ to provide sufficient contact area for the outer coaxial electrode used. 


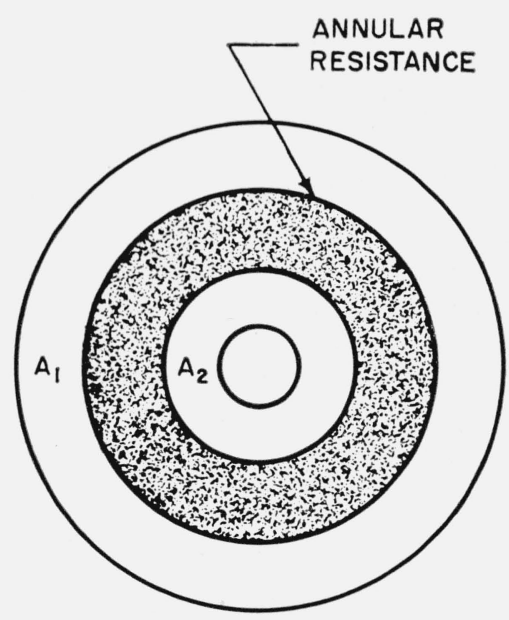

FIGURE 5. Sketch of a carbon disk for the clamped-type element, showing the annular resistive area and the painted contact rings.

\section{$\mathbf{A}_{1}$, Painted ring (outside); $\mathbf{A}_{2}$, painted ring (inside).}

There are, undoubtedly, many ways of cutting disks from the carbon-coated card material. The method used provided quite satisfactory results, whether cutting one or a large number of disks at a time. The sheet material was placed face down on a smooth, flat surface, and squares about $1 / 8$ in. larger than the desired outside diameter of the finished disk were individually cut on power shears. The squares were stacked, clamped between flat metal plates, drilled, and turned to size on a lathe. Airdrying silver paints (Linnick Chemical Co. air-drying silver lacquer or DuPont silver conducting paint No. 4817) were used for concentric areas to be in contact with the electrodes. Either was applied with a camel's-hair brush after masking the annular ring area. High precision in this operation was found unnecessary. The drying process was accelerated by the application of heat from an infrared lamp for a short time.

Returning now to figure 4, parts $\mathrm{G}, \mathrm{D}, \mathrm{CR}, \mathrm{CN}$, and CPL are shown assembled to form the core of the unit. The contact resistance was to be less and remain less than 1 milliohm. It was found important that the surfaces of G and CPL against which the disk was clamped be coplanar, and parallel with the surface F, the faces of GR, and the surface G of part $\mathrm{N}$, and that all were normal to the axis of the assembly. Stable and positive contact between the electrodes and the disk was obtained with tin- or lead-foil washers 2 to 5 mils thick. These washers were cut to fit exactly over the silver contact areas and were placed between the disk and the electrodes GR and CP. In clamping the disk into place, care was taken to prevent turaing of the parts. This was accomplished by pinning $\mathrm{CP}$ to $\mathrm{CPL}$, and GR to $\mathrm{G}$. The pins used for this purpose fitted loosely so as not to prevent these parts from resting flat against the disk. The shank of CP fitted freely into CPL and surface $\mathrm{F}$ was undercut slightly at $\mathrm{C}$ for the same reason. In the figure, the edges of the elec- trodes appear quite rounded. All that was required, actually, was to break the edges enough to remove sharp irregularities that could damage the resistive film and prevent the electrodes from seating properly.

Clamped assemblies were found unsatisfactory for low-value resistance units. Nichrome foil, which had suitable resistivity, was too hard. It failed to form to the electrodes resulting in spotty contact at only a few points. Such a unit, because of lack of electrical symmetry, exhibited reactance at relatively low frequencies. The noble metals that were required as thin foils $(2.5 \mu$ thick for resistance of 1 to 10 milliohms) proved to be too soft. Under the pressure of contact, they flowed sufficiently to cause a deterioration of contact to the point where the contact resistance became comparable with the foil resistance.

\subsection{Fired Paints}

Where stable elements of less than $1 \mathrm{ohm}$ were needed, the construction illustrated in figure 6 produced good results. A dielectric, D, of glass or ceramic, completely covered, except on one end, by a very thin coating of fired-on conductive paint was soldered to the inner and outer electrodes $\mathrm{G}$ and $\mathrm{P}$. That portion of the film covering the end of $D$ constituted the resistive annular ring. Inasmuch as the electrodes were soldered directly to the metal film comprising the resistive element, a properly soldered unit was free from the contact resistance difficulties encountered with the clamped assembly. Many conducting paints and pastes of platinum, gold, silver, and combinations of these were tried. Those listed in table 2 were selected because resistive films made from these possessed the requisite stability adhered well to their substrates, and had less tendency to alloy with the solder in the assembling proc-

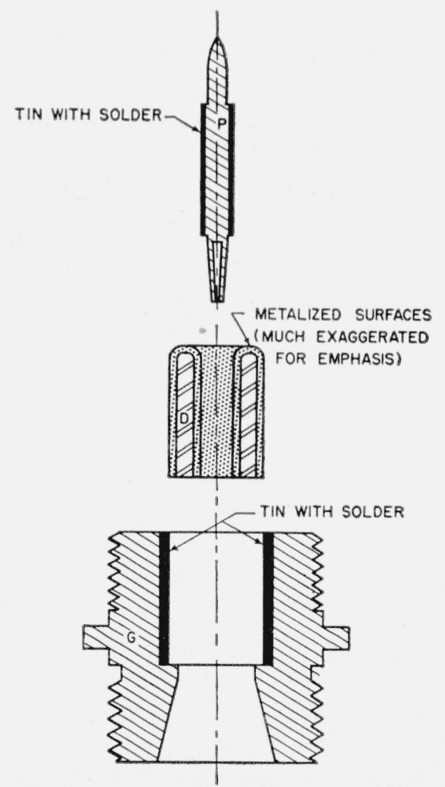

Figure 6. Cross-sectional view of an element using a glass or ceramic sleeve metallized by the fired-paint technique. 
TABLE 2. Approximate data for using fired paints as resistive elements

\begin{tabular}{|c|c|c|c|c|c|c|}
\hline Type of paint & $\begin{array}{l}\text { Dilution } \\
\text { with } \\
\text { turpentine }\end{array}$ & Substrate & $\begin{array}{l}\text { Firing } \\
\text { temperature }\end{array}$ & $\begin{array}{l}\text { Resistance } \\
\text { obtained }\end{array}$ & $\begin{array}{c}\text { Resistivity } \\
\text { (From mfg. } \\
\text { data) }\end{array}$ & $\begin{array}{l}\text { Approximate } \\
\text { diameter } \\
\text { ratios }\end{array}$ \\
\hline $\begin{array}{l}\text { Hanovia No. } 1 \text { (platinum bright, } \\
\text { containing gold and platinum }\end{array}$ & $\begin{array}{l}\text { Percent } \\
\text { None }\end{array}$ & $\begin{array}{l}\text { Ceramic or pyrex } \\
\text { glass. }\end{array}$ & ${ }^{\circ} \mathrm{F}$ & 0.3 to 0.7 ohms $\ldots . .$. & $\begin{array}{c}\text { Ohms/cm² } \\
13 \text { (film } 0.1 \mu \text { thick) }\end{array}$ & $1.5: 1$ to $2.3: 1$ \\
\hline $\begin{array}{l}\text { Hanovia No. } 12 \text { (platinum in sus- } \\
\text { pension). }\end{array}$ & $15 \ldots$ & Ceramic & $\begin{array}{l}1,200 \text { (leave door of } \\
\text { oven open until } 800^{\circ}\end{array}$ & 18 milliohms & & $2.3: 1$ \\
\hline $\begin{array}{c}\text { Hanovia No. } 14 \text { (platinum alloy } \\
\text { paste). }\end{array}$ & Up to $50 \ldots$ & Pyrex or ceramic & F is reached) & 30 to 43 milliohms & $\begin{array}{l}0.75 \text { to } 0.85 \text { when } \\
\text { thinned } 15 \text { percent. }\end{array}$ & $1.5: 1$ to $2.3: 1$ \\
\hline Hanovia 14 & Unthinned - & _... do do _._._. & 1,200 & 10 to 18 milliohms & _._do & $1.5: 1$ to $2.3: 1$ \\
\hline Hanovia No. 38 (silver paste) ... & $10 \ldots \ldots$ & $\begin{array}{l}\text { Gold and glass or } \\
\text { ceramic. }\end{array}$ & 1,000 to $1,300_{\ldots}$ & 1 milliohm & $\begin{array}{l}0.04(0.1-\mathrm{mil} \text { thick } \\
\text { film). }\end{array}$ & \\
\hline
\end{tabular}

ess. The information contained in this table was intended to serve merely as a rough guide in the design and construction of elements. In practice, the resistivity of any of these paints varied as much as 100 percent from the values shown because it depended upon such factors as the degree of dilution, the manner of application, the manner of firing, and the condition of the surface of the substrate. Therefore, only an approximation of $\gamma$ for a particular value of disk resistance could be determined from eq (4).

The first step in assembling a fired element was to select the proper substrate for the particular conductive paint to be used. This was important because many paints are intended for firing to a particular base material. Should this paint be fired on a base for which it was not intended, poor bonding to that base could result, and the finished element would be mechanically fragile. Because the paints fired at a temperature of approximately $1,400^{\circ} \mathrm{F}$, only a Pyrex glass or a ceramic material capable of withstanding this temperature without undue stressing or distortion could be used.

Dielectric bushings with end faces perpendicular to their axes were cut from glass or ceramic tubing, using a thin glass-cutting wheel. One end face was polished to provide the smoothest possible surface and its edges were slightly rounded. In the case of glass, this was easily done by fire-polishing the end with the flame of a torch; with ceramic, this was much more difficult and the finished surface was rather porous. Consequently, commercially available glazed ceramic insulators of the style illustrated in figure 7 , a, were used. With this configuration for $\mathrm{D}$, the outer electrode, $\mathrm{G}$, needed modification, as shown in figures $7, \mathrm{~b}$, and 8 .

Before applying conductive paint to the insulator, the surfaces were thoroughly cleaned with acetone to remove all foreign matter. Once cleaned, the insulator was handled only with tweezers. A single thin coating of conducting paint, properly thinned, was applied with a small brush to all surfaces except the end having the unrounded edges, and care was taken to see that it bridged the rounded edges to form a continuous film. For applying the paint uniformly, the insulator was held vertically in a motor-driven jig, figure 9, and the paint applied as it was slowly rotated. Difficulty was encountered in coating the inside surface of the center hole when the diameter was less than $3 / 16$ in.
All the paints listed in table 2, with one exception, were fired in the same manner. After the paint had air-dried until it was no longer sticky, the insulator was placed in an electric muffle furnace at room temperature. The furnace was then slowly heated until the firing temperature was reached. When firing Hanovia No. 12, the furnace door was left open until a temperature of about $800^{\circ} \mathrm{F}$ was obtained to allow a copious supply of air for oxidizing the solvents in the paint. At this point the door was closed and the heating cycle continued until the oven reached the maximum temperature of firing, $1,400^{\circ} \mathrm{F}$. When using the other paints listed, it was unnecessary to leave the door open at any stage. Once the furnace arrived at the maximum temperature, it was kept at this heat for about 10 minutes and then allowed to cool slowly to prevent internal stressing of the dielectric during cooling. The platinum-coated insulators were then burnished, washed with acetone, silver contact rings painted on, and refired as before.

Prior to soldering the metallized insulator into its electrodes, the film was burnished with fine steel wool, washed with acetone, and a mask applied to the annular portion to prevent the solder from flowing over it. Sauereisen Cement No. 78 was used. This air-drying compound was thinned with water to the desired consistency and applied by brush to cover the end face and the rounded edges. If these edges had been left unmasked, the solder would have flowed over them to form wedge-shaped extensions to the electrodes, with the result that the $r-f$ resistance at high frequencies would have been more than its d-c value. After the masking had dried, the exposed areas of the film were burnished and washed again and Divco flux No. 300 immediately applied. Any delay in applying this flux may result in contamination of the surface.

The next step was to prepare the electrodes for the assembling operation. They were placed into a duralumin jig, as shown in figures 10 , a and $b$, and 11 , to position them so that the insulator could be dropped into place and soldered in. In addition to its function of holding the pieces, the jig conveyed heat by conduction to both members simultaneously. The pieces were heated only enough to cause the Diveo 233 solder to melt and flow smoothly. Then the surfaces indicated in figures 6 and 7 , b, were liberally tinned with this solder and the metallized insulator dropped into place between the electrodes 


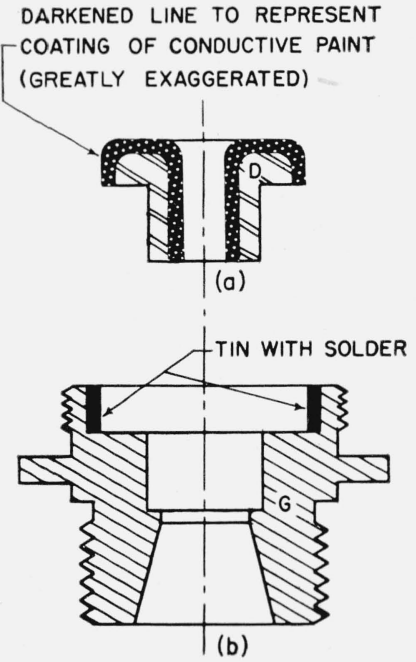

Figure 7. Cross section of commercial ceramic insulator and outer electrode.

a, metalized surfaces: $\mathbf{b}$, modified construction of outer electrode to fit the ceramic insulator emphasizing areas to be tinned.

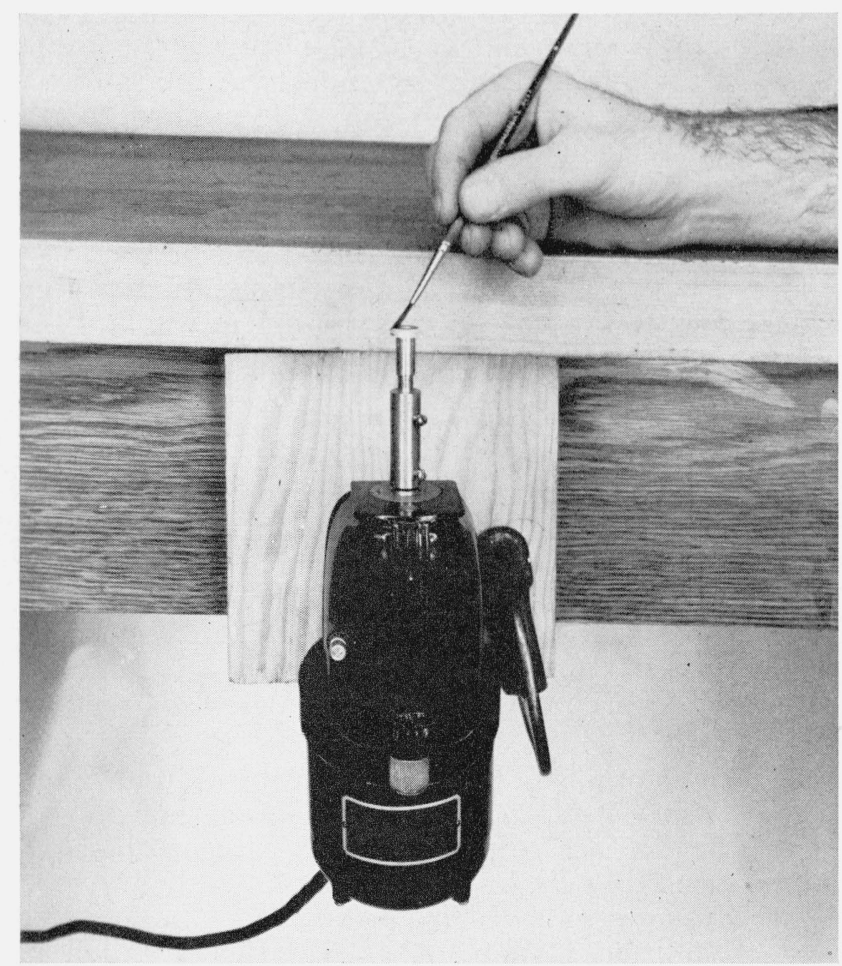

Figure 9. A motor-driven jig for painting ceramic buttons.
Figure 8. Completed resistive element and its component parts, including the brass outer electrode, the metallized ceramic insulator, and the metal center pin.
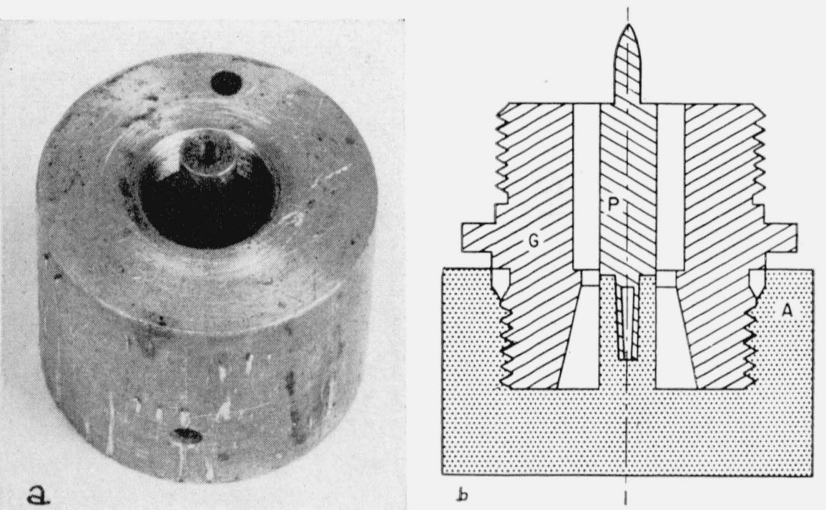

Figure 10. Duralumin jig.

a, Jig; b, cross section showing coaxial electrodes in place preparatory to soldering the assembly.

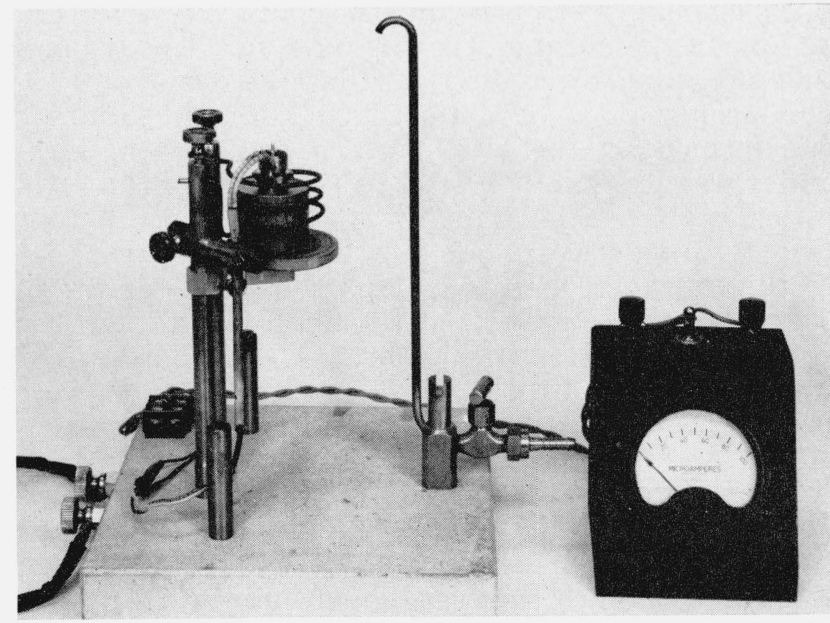

Figure 11. Heating element used for soldering the resistive button to its electrodes, with the dural jig in place and a pyrometer for determining the temperature of the electrodes. 


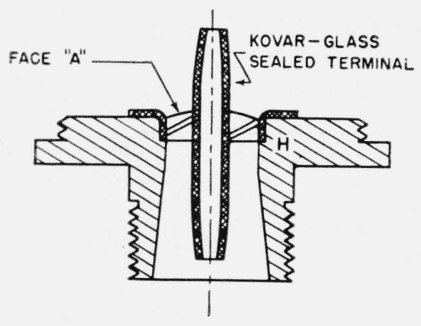

FIGUKE 12. Cross-sectional view of a resistive element using a Kovar-glass seald terminal for the electrodes and supporting substrate for a resistive film.

Face $A$ is metalized to form the resistive annulus.

and gradually worked about until it was properly seated. The fit between the parts was a loose one to permit the flow of solder between them to form a solid electrical and mechanical bond over the whole circumference of each junction. Very low-temperature melting solder was not found satisfactory as it produced a poor mechanical bond. While enough solder was used to insure good bonding completely around the circumferences of the electrodes, the excessive use of solder often resulted in shorting of the element, the excess flowing through the unit completely and bridging the dielectric on the under side.

When thinning a conducting paint with turpentine, only the amount to be used in a given day was prepared. Where large quantities were prepared at one time and left in storage, the solvents gradually evaporated resulting in a more concentrated mixture which had higher conductivity. Moreover, as the concentration increased, a single coating produced a thicker film. Consequently, elements made at different times from the same mixture had widely different resistance values.

\subsection{Evaporated and Plated Elements}

Resistive elements of approximately 1 milliohm were also constructed by another method, in which the resistive film was deposited by the evaporation ${ }^{6}$ and plating of pure silver on a flat surface consisting of the coaxial electrodes and the separating dielectric. In one type, using this technique, Kovar-glass sealed terminals were used, as illustrated in figure 12 . The proper ratio of diameters, $\gamma$, for the annular ring formed by the glass surface between the electrodes was determined from eq (4); but, as the ratio varied within rather narrow limits for the different type terminals available, the over-all physical size of the terminal became the prime consideration. Only those having a face reasonably flat and free from sharp irregularities or breaks, especially at the lines of juncture between glass and metal, were used. The terminals selected had all metal surfaces tinned and had an approximate $\gamma$ of $2: 1$ and an over-all diameter of about $1 / 2$ in. with a center electrode, which was tubular. Before soldering one into its brass shell, the center electrode was shaped at both ends into fingered female pins similar to a type N.

${ }^{6} \mathrm{H}$. W. Weinhart and H. G. Wehe, Metal electrodes deposited on quartz crystals by the evaporation process; R. A. Heising, Quartz crystals for electrical eircuits, p. 333-355 (D. Van Nostrand, New York, N. Y., 1946).
Better elements resulted when the evaporated and plated silver film was deposited on silver-plated electrodes. Each step necessary in depositing the evaporated and plated film is listed in the following text. To silver plate the electrodes:

a) The tinning was dissolved from the Kovar with $\mathrm{HCl}$.

b) The exposed metal surfaces were scrubbed under tap water using a fine abrasive, and rinsed.

c) A copper flash was applied immediately in a copper-cyanide plating bath (a necessary step since unprotected Kovar oxidized very quickly if left exposed to the air).

d) After rinsing in tap water, a silver strike was applied in a standard silver-cyanide strike solution and this was followed by plating 2 to 5 ten-thousandths of an inch of silver in a standard cyanide plating bath.

e) After rinsing once more in tap water, the surfaces were cleaned with acetone and dried. Then the resistive film was formed as follows:

f) A thin silver film approximately $0.1 \mu$ thick was evaporated upon the entire surface.

g) The silver was built up to a total thickness of no more than $2.5 \mu$ by plating in a standard high-concentration plating bath.

Steps e, f, and $g$ were performed as quickly as possible. A delay between these successive steps of as little as 1 hour was enough for contamination of the surfaces to occur, resulting in poor electrical contact between the film and the electrodes. A final protective coating of lacquer, Krylon, was applied to the surface to prevent mechanical injury.

The second type of unit was similar to that described in the section devoted to the fired-paint technique. After the metallized insulator was soldered between the electrodes, the conductive film on the end of the button was ground away, and the electrodes and the insulator were ground until the face that they presented was flat and free from flaws, particularly where the metal and dielectric joined. Once again, all exposed metal surfaces were silver plated before evaporating upon them. However, when silver was plated directly upon the electrodes, it did not cover the thin ring of solder on the surface at the lines of juncture between the dielectric and metal. All processing steps required in depositing the evaporated and plated film on this type unit are listed below. To cover the electrodes with a silver plate:

h) The metal surfaces were scrubbed under tap water using a fine abrasive and then rinsed.

i) The unit was dipped into 20-percent $\mathrm{HCl}$ and rinsed again in tap water.

j) This was followed by a dip into a hot caustic solution (2 percent of $\mathrm{NaOH}$ per gallon of water at $\left.150^{\circ} \mathrm{F}\right)$.

k) The metal surfaces were then scrubbed and rinsed in tap water.

Upon completion of step $\mathrm{k}$, the remaining steps, namely, copper flashing, silver flashing and silverplating of the electrodes, the evaporation of the silver 
film and the final plating were the same as steps c through g. Aluminum, the only other metal tried in this process, gave unsatisfactory results because of poor adherence to the substrata.

\section{Conclusion and Implications for Further Work}

The processes described above are by no means the only ones by which resistive elements may be fabricated. However, there is sufficient experimental data on resistive elements made by these methods to prove their dependability. A chemical reduction process, commonly known as the silvermirror process, is presently under consideration. The steps in the procedure are much the same as those outlined in the last section, with the exception that the chemical reduction of silver replaces the final steps of evaporation and plating.

From preliminary tests on a recently completed group of 1 - to 5-ohm elements made with fired-on paints, it appears that this may be a simpler method than the clamped carbon type for fabricating high- resistance elements ( 1 to $10 \mathrm{ohms}$ ). Further tests are necessary to determine their stability.

No attempt was made to reproduce resistance values within any specific tolerance. The carbon sheet material used in the clamped assemblies has a specified tolerance of \pm 10 percent, and consequently no element of this construction can be expected to be reproduced closer than this. The process that probably would lend itself best to close resistance tolerances is the one using the fired-on paints. It is conceivable that by controlling the degree of dilution and by using some other means of applying the paint, such as spraying or dipping, resistance values could be reproduced to within 5 to 10 percent.

Credit should be given to Vernon A. Lamb anc' William H. Metzger, Jr., for their valuable cooperation and technical assistance in investigating the various chemical problems encountered in making thin metallic film.

Washington, May 1953. 